\title{
Habitat Characterization of Black Flies (Diptera: Simuliidae) in the Tafna Catchment of Western Algeria
}

\author{
Chafika Chaoui Boudghane-Bendiouis ${ }^{1}$, Karima Abdellaoui-Hassaïne ${ }^{1 *}$, Boutaïna Belqat ${ }^{2}$, \\ Evelyne Franquet ${ }^{3}$, Samira Boukli Hacene ${ }^{1}$, Baya Yadi ${ }^{1}$ \\ ${ }^{1}$ Laboratory of Valuation of the Actions of the Man for the Environmental Protection and the Application in \\ Public Health, University of Tlemcen, Tlemcen, Algeria \\ ${ }^{2}$ Laboratory of Ecology, Biodiversity and Environment, Faculty of Sciences, University Abdelmalek Essaâdi, \\ Tetouan, Morocco \\ ${ }^{3}$ Institut Méditerranéen de Biodiversité et d’Ecologie Marine et Continentale (IMBE), Université Aix-Marseille, \\ Provence, France \\ Email: bendiouisch@yahoo.fr, ${ }^{*}$ hassaine69@hotmail.com, belqat@gmail.com, \\ evelyne.franquet@univ-cezanne.fr
}

Received 5 November 2014; revised 7 December 2014; accepted 13 December 2014

Academic Editor: Victor R. Savage National University of Singapore, Singapore

Copyright (C) 2014 by authors and Scientific Research Publishing Inc.

This work is licensed under the Creative Commons Attribution International License (CC BY). http://creativecommons.org/licenses/by/4.0/

(c) (i) Open Access

\begin{abstract}
Physical Habitat characterization of black flies was performed in the Tafna Basin of Algeria, based primarily on stream size, substrate, and aquatic and riparian vegetation. A total of 143 samples were taken between April and October 2009 at 11 sampling sites in the Tafna catchment. Dams exerted an effect through a slowdown of flow and sedimentation of fine particles, eliminating coarse microhabitats favorable for black flies. Stream and substrate characteristics are key parameters that determined the microhabitats of the species. Of 10 species considered, four were widely present with significant plasticity for the stream and substrate. Four other species were more closely associated with faster streams and eroded substrate. A greater rheophilic tendency was found for Simulium bezzii (Corti), Simulium sergenti Edwards, Simulium quadrifila Grenier, Faure and Laurent and Simulium galloprovinciale Giudicelli, which represents a new record for Algeria.
\end{abstract}

\section{Keywords}

Mediterranean Fauna, Aquatic Insects, Diversity, Ecology, Microhabitat, Microdistribution

\footnotetext{
${ }^{*}$ Corresponding author.
}

How to cite this paper: Boudghane-Bendiouis, C.C., Abdellaoui-Hassaïne, K., Belqat, B., Franquet, E., Hacene, S.B. and Yadi, B. (2014) Habitat Characterization of Black Flies (Diptera: Simuliidae) in the Tafna Catchment of Western Algeria. Open Journal of Ecology, 4, 1014-1024. http://dx.doi.org/10.4236/oje.2014.416084 


\section{Introduction}

Among the benthic macroinvertebrates of Algerian wadis, larvae and pupae of Diptera Simuliidae have received less attention. Apart from the first inventory [1], the early studies were devoted to the description of species but rarely to their ecology [2]-[5]. During the last three decades, the only available ecological data are scarce [6]-[8] and more recently those of Chaoui Boudghane-Bendiouis [9] and Cherairia [10].

The present study, performed 25 years after the work by Gagneur and Clergue-Gazeau [6] on Simuliidae in the Tafna catchment, aims to identify the faunal composition, to provide update simuliid geographic observations and understand the organization of the community by analysis of the micro-distribution of species within differentiated microhabitats according to the current-substrate complex. The concept of a relationship between the specific characteristics of microhabitats and the micro-distribution of macroinvertebrates has been highlighted by numerous authors [11]-[14].

\section{Materials and Methods}

\subsection{Study Site}

Wadi Tafna, which is located in northwestern Algeria, originates from the Tlemcen Mountains (Tell Atlas) and flows $170 \mathrm{~km}$ to the north and empties into the Mediterranean Sea. Its catchment area is about $7245 \mathrm{~km}^{2}$ (Figure 1).

Tafna catchment mainly includes two geological structures: Tlemcen Mountains in the south, containing dolomitic terrains rich in carbonates of the Upper Jurassic, and the plain of Remchi in the north, consisting of clay-sandstone deposits of the Miocene. Valley bottoms are covered with alluvial Quaternary deposits [15]. The regional climate is Mediterranean with mild and wet winters; it is semi-arid over the entire catchment.

The upstream lands are highly cracked and karst-like, which gives them high permeability and a significant flow of groundwater that emerges at the surface as springs [16]. This provides the upstream wadis with some hydrological stability. In contrast, the downstream basin receives irregular and mostly seasonal rainfall, which results in a series of floods and low water periods in wadis at medium and low altitudes [17]. In the immediate vicinity of the upstream sites, the land is partly used for limited market gardening. Downstream, crop growing predominates in the plain, alternating with vegetable crops. These are irrigated by pumped water that affects the flow of streams.

\subsection{Sampling Methods}

Sampling was carried out at seven sites along wadi Tafna, one site in wadi Khemis, another in wadi Chouly, and two other sites in wadi Isser, the main tributary of wadi Tafna (Figure 1). To achieve representative sampling of the catchment, the 11 sites were randomly drawn from upstream to downstream. Three classes of sampling sites were selected (1) sites of high Tafna, from 0.5 to $11.5 \mathrm{~km}$ from the source and located between 1090 and $650 \mathrm{~m}$ altitude, (2) sites of middle Tafna, from 50 to $54.5 \mathrm{~km}$, at altitudes between 303 and $220 \mathrm{~m}$, and (3) sites of low Tafna at more than $75 \mathrm{~km}$ with an altitude between 83 and $45 \mathrm{~m}$.

Benthic samples were taken using a Surber sampler (mesh net $300 \mu \mathrm{m}$ ), considering four main physical factors: current velocity, type of substrate, and aquatic and riparian vegetation. Measurements of the instantaneous stream velocity, using the weighted float technique [6], allowed five classes of currents velocity to be identified (VF: very fast, F: fast, M: medium, S: slow, VS: very slow). The substrate nature (Table 1) was determined from the erosion facies (coarse grains: rocks, stones and pebbles) or from sedimentation (fine grains: sand, silt, and mud). Three types of substrates were defined as eroded, deposited and heterogeneous (fine and coarse elements). Aquatic vegetation included all living organic materials in the form of dense herbs, submerged and emergent spermaphytes, and bryophytes and algae. The riparian vegetation was assessed through plant stratification (herbaceous, shrubby and arborous). Thus, 143 samples were collected at 11 sampling sites in 2009 (March to November). The sampling effort was the same for all sites, at the rate of two outlets per month, but the number of samples per site was linked to the specific spatial heterogeneity.

The black flies were counted and determined morphologically to species level, using the analytic key and descriptions of Simuliidae of Morocco [18]. 


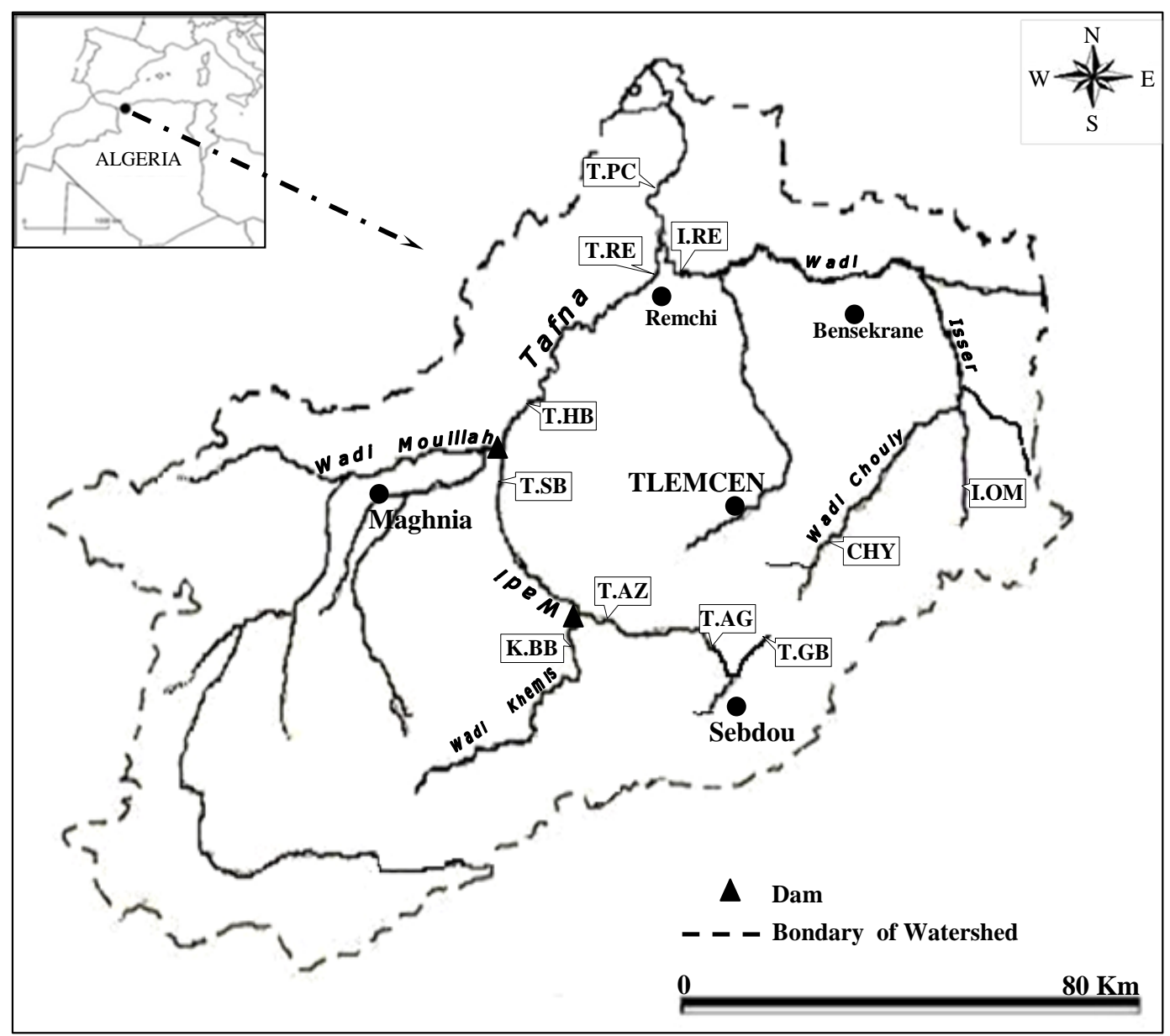

Figure 1. Map of the Tafna River Basin in western Algeria, showing locations of sampling sites for simuliids.

Table 1. Geographical and physical characteristics of sampling sites in Tafna River Basin, Algeria (March-November 2009).

\begin{tabular}{|c|c|c|c|c|c|c|c|c|c|c|c|}
\hline Sites & Longitude & Latitude & $\begin{array}{l}\text { Altitud } \\
\text { (m) }\end{array}$ & Orientation & $\begin{array}{l}\text { Distance } \\
\text { from the } \\
\text { source }\end{array}$ & $\begin{array}{l}\text { Width of } \\
\text { riverbed } \\
\text { (m) }\end{array}$ & $\begin{array}{l}\text { Dominant } \\
\text { substrate }\end{array}$ & Turbidity & $\begin{array}{l}\text { Maximum } \\
\text { depth }(\mathrm{cm})\end{array}$ & $\begin{array}{l}\text { Riparian } \\
\text { vegetation }\end{array}$ & $\begin{array}{l}\text { Human } \\
\text { impact }\end{array}$ \\
\hline T.GB & $1^{\circ} 18^{\prime} 42^{\prime \prime}$ & $34^{\circ} 41^{\prime} 3^{\prime \prime}$ & 1090 & $\mathrm{~N}-\mathrm{S}$ & 0.56 & 3 & $\mathrm{P}$ & $\mathrm{C}$ & 60 & $\mathrm{Hb}$ & $\mathrm{A}, \mathrm{Gz}$ \\
\hline T.AG & $1^{\circ} 22^{\prime} 16^{\prime \prime}$ & $34^{\circ} 41^{\prime} 56^{\prime \prime}$ & 787 & SE-N & 8.35 & 3 & $P, G, S$ & $\mathrm{C}$ & 100 & Ps & A \\
\hline T.AZ & $1^{\circ} 27^{\prime} 52^{\prime \prime}$ & $34^{\circ} 41^{\prime} 42^{\prime \prime}$ & 664 & SE-NO & 11.44 & 5 & S, M & $\mathrm{T}$ & 60 & Ps & A \\
\hline T.SB & $1^{\circ} 39^{\prime} 14^{\prime \prime}$ & $34^{\circ} 49^{\prime} 31^{\prime \prime}$ & 303 & SE-NW & 49.90 & 7 & $\mathrm{P}, \mathrm{S}$ & $\mathrm{T}$ & 40 & Sh & A \\
\hline T.HB & $1^{\circ} 37^{\prime} 39^{\prime \prime}$ & $34^{\circ} 55^{\prime} 31^{\prime \prime}$ & 220 & SW-NE & 54.43 & 8 & S, M, Si & $\mathrm{T}$ & 50 & Sh & A \\
\hline T.RE & $1^{\circ} 27^{\prime} 51^{\prime \prime}$ & $35^{\circ} 04^{\prime} 35^{\prime \prime}$ & 83 & SW-NE & 78.40 & 20 & $\mathrm{M}, \mathrm{Si}$ & $\mathrm{T}$ & 50 & Sh & A \\
\hline T.PC & $1^{\circ} 26^{\prime} 58$ & $35^{\circ} 08^{\prime} 37^{\prime \prime}$ & 45 & S-N & 85.52 & 20 & M, Si & $\mathrm{T}$ & 40 & $\mathrm{Hb}$ & A \\
\hline K.BB & $1^{\circ} 30^{\prime} 20^{\prime \prime}$ & $34^{\circ} 40^{\prime} 57^{\prime \prime}$ & 650 & S-N & 19.70 & 30 & $\mathrm{M}, \mathrm{Si}$ & $\mathrm{T}$ & 1500 & $\mathrm{Hb}$ & A \\
\hline CH.Y & $1^{\circ} 9^{\prime} 58^{\prime \prime}$ & $34^{\circ} 50^{\prime} 26^{\prime \prime}$ & 850 & SE-NW & 10.22 & 3 & $\mathrm{R}, \mathrm{P}$ & C & 40 & Sh & A \\
\hline I.OM & $1^{\circ} 00^{\prime} 52^{\prime \prime}$ & $34^{\circ} 54^{\prime} 08^{\prime \prime}$ & 870 & SW-NE & 1.15 & 4 & $\mathrm{P}, \mathrm{M}, \mathrm{Si}$ & $\mathrm{T}$ & 70 & Ps & A \\
\hline I.RE & $1^{\circ} 26^{\prime} 32^{\prime \prime}$ & $35^{\circ} 05^{\prime} 40^{\prime \prime}$ & 80 & S-N & 66.77 & 5 & M, Si & $\mathrm{T}$ & 60 & Ps & A \\
\hline
\end{tabular}

$\mathrm{R}=$ rocks, $\mathrm{P}=$ cobble, $\mathrm{G}=$ gravel, $\mathrm{S}=$ sand, $\mathrm{Si}=$ silt, $\mathrm{M}=$ mud, $\mathrm{C}=$ clear, $\mathrm{T}=$ turbid, $\mathrm{Ps}=$ pluristratified, $\mathrm{Sh}=$ shrublands, $\mathrm{Hb}=$ herbaceous, $\mathrm{A}=$ agriculture, $\mathrm{Gz}=$ grazing. 


\subsection{Data Processing}

The spatio-temporal distribution of black flies was first studied using a factorial analysis (AFC) from the data matrix, taking into account species abundances only in prolific samples containing at least two individuals. An analysis of inertia was then performed to assess the proportion of variability explained by each of the five variables: five variables: station, month of sampling, stream velocity, substrate nature and class of distance from the source. A Monte Carlo Permutation Test was performed to test the significance of this variability. The dot plot was used to illustrate the distribution of species abundance for each site. These statistical analyses were performed using Minitab 16.1 statistical software.

The structure of black fly communities for each site was determined by calculating diversity indices: specific richness $\mathrm{S}$, Margalef index (Dmg $=\mathrm{S}-1 / \mathrm{ln}(\mathrm{N}))$, Shannon index $\left(H^{\prime}=-\Sigma\right.$ pilnpi), and Piélou index $\left(J^{\prime}=\right.$ $H^{\prime} / H \max$ ). Hierarchical Cluster Analysis (HCA), performed from the matrix of samples for black flies and the studied physical characteristics, was used to measure the degree of similarity, according to the euclidean distances and aggregation, using Ward's method (moment of second order).

\section{Results}

\subsection{Faunal Composition and Biogeographic Considerations}

Ten species were recorded among more than 7208 specimens (Table 2). All belong to the genus Simulium, represented by five subgenera, namely Eusimulium, Nevermannia, Simulium, Trichodagmia, and Wilhelmia. The most frequent species in our samples have a wide Palaearctic distribution. These species include S. velutinum, $S$. ornatum (complex), S. trifasciatum and S. pseudequinum. Simulium intermedium is widespread in Europe and also in northwest Africa.

Some less abundant and less frequent species have either a Mediterranean distribution (S. bezzii and S. galloprovinciale) or an Ibero-Maghreb distribution with limited extension (S. sergenti and S. quadrifila). Simulium ruficorne has an Ethiopian distribution.

\subsection{Spatial Distribution of Black Flies}

Of all samples (143), 70\% did not contain black flies; 38.5\% of these were taken from areas with slow current and a deposited substrate consisting of fine sediments (sand, silt, and mud), 26.6\% from fine substrate colonized by aquatic vegetation forming dense herbaceous growth, and $4.9 \%$ from a bottom covered with algae. These habitats were predominant at sites K.BB and T.SB. Although located in high and medium Tafna, these sites are upstream of dams (Beni Bahdel and Hammam Boughrara, respectively).

The presence of these dams results in slow flow, homogenization of facies, and sedimentation of fine elements, eliminating coarse microhabitats favorable for black flies. Inertia analysis showed that the highest inertia percentage concerns the variable station (68.8\%) with a significant difference, according to the Permutation Test

\section{Table 2. Total numbers of 10 species of Simulium collected in the Tafna River Basin, Algeria.}

\begin{tabular}{cllc}
\hline Subgenus & \multicolumn{1}{c}{ Group } & \multicolumn{1}{c}{ Species } & Numbers \\
\hline Eusimulium & & S. velutinum (Santos Abreu) (complex) & 1353 \\
Nevermannia & S. (N.) ruficorne & S. ruficorne Macquart & 1 \\
& S. (S.) bezzii & S. bezzii (Corti) & 385 \\
Simulium & S. intermedium Roubaud & 898 \\
& S. (S.) ornatum & S. ornatum Meigen (complex) & 1489 \\
Trichodagmia & S. trifasciatum Curtis & 2149 \\
& S. galloprovinciale Giudicelli & 12 \\
Wilhelmia & S. pseudequinum Séguy & 897 \\
& S. quadrifila Grenier, Faure and Laurent & 6 \\
\hline
\end{tabular}


$(p=0.019)$, revealing that distributions would primarily be determined by the factor station; $p$ remained insignificant for the other four variables analyzed.

At all the sites, the Margalef index values were less than 2 and the index $H$ ' fluctuated between 1.97 and 0.97 , indicating low diversity. However, the values of the index $J^{\prime}$, always greater than 0.5 , indicated the presence of regular and balanced communities (Table 3).

The communities of upper Tafna sites (T.GB, T.AG, T.AZ, and CH.Y) displayed the greatest specific richness due to certain typical species. Simulium galloprovinciale was collected exclusively in wadi Chouly (CH.Y) and S. quadrifila at site T.AG (Figure 2). Upstream of Beni Bahdel dam, the two sites T.AG and T.AZ have $S$. sergenti. However, S. bezzii is abundant in samples from three upstream sites (T.GB, T.AG and CH.Y). Moreover, the lowland sites have mostly species such as $S$. velutinum, S. trifasciatum, and S. pseudequinum. These species, the most abundant and ubiquitous taxa, are constant over the entire Tafna catchment (Figure 2).

\subsection{Microhabitats}

The 42 prolific samples tested with respect to the main physical characteristics are shown in a dendrogram, resulting from hierarchical cluster analysis (HCA) (Figure 3). Twelve groups were found, each corresponding to a

Table 3. Diversity index of simuliid communities at sampling sites in the Tafna Basin, Algeria.

\begin{tabular}{ccccccc}
\hline Sites & DS & N & S & D.mg & $H^{\prime}$ & $J^{\prime}$ \\
T.GB & 1 & 307 & 4 & 1.75 & 1.79 & 0.89 \\
T.AG & 1 & 2313 & 8 & 1.96 & 1.97 & 0.65 \\
T.AZ & 1 & 146 & 5 & 1.85 & 1.94 & 0.83 \\
T.HB & 2 & 22 & 4 & 1.11 & 1.36 & 0.68 \\
T.RE & 3 & 666 & 3 & 1.27 & 1.28 & 0.81 \\
T.PC & 3 & 242 & 3 & 0.95 & 0.97 & 0.61 \\
CHY & 1 & 3157 & 6 & 1.81 & 1.82 & 0.70 \\
I.OM & 1 & 20 & 2 & 0.5 & 1 & 1.22 \\
I.RE & 3 & 335 & 5 & 1.18 & 0.52 \\
\hline
\end{tabular}

DS = class of distance from the source, $\mathrm{N}=$ sample size, $\mathrm{S}=$ specific richness, D.mg = Margalef index, $H^{\prime}=$ Shannon index, $J^{\prime}=$ eveness.

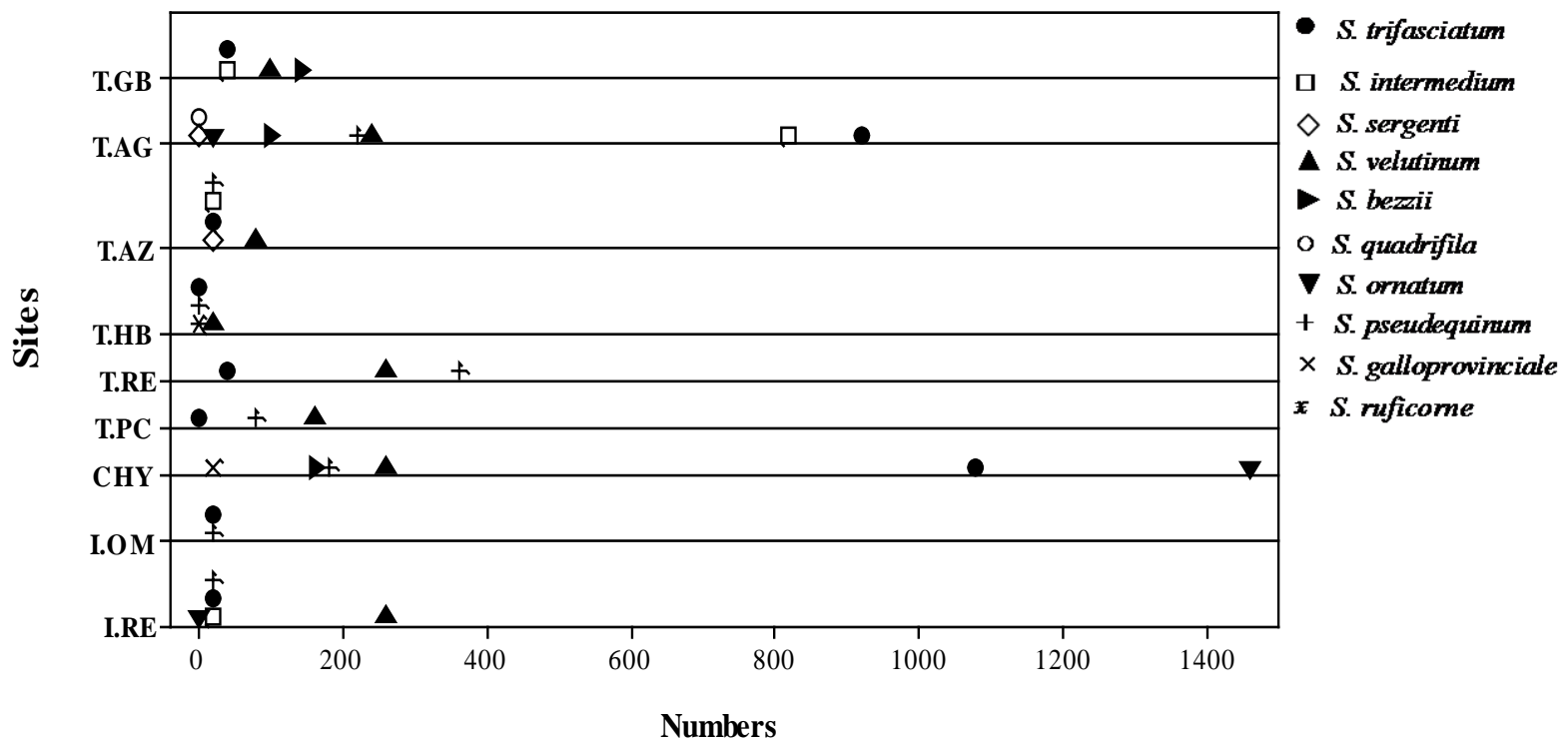

Figure 2. Dot plot showing the spatial distribution of the total number of specimens per species of Simuliidae in the Tafna Basin of Algeria (March-November 2009). 


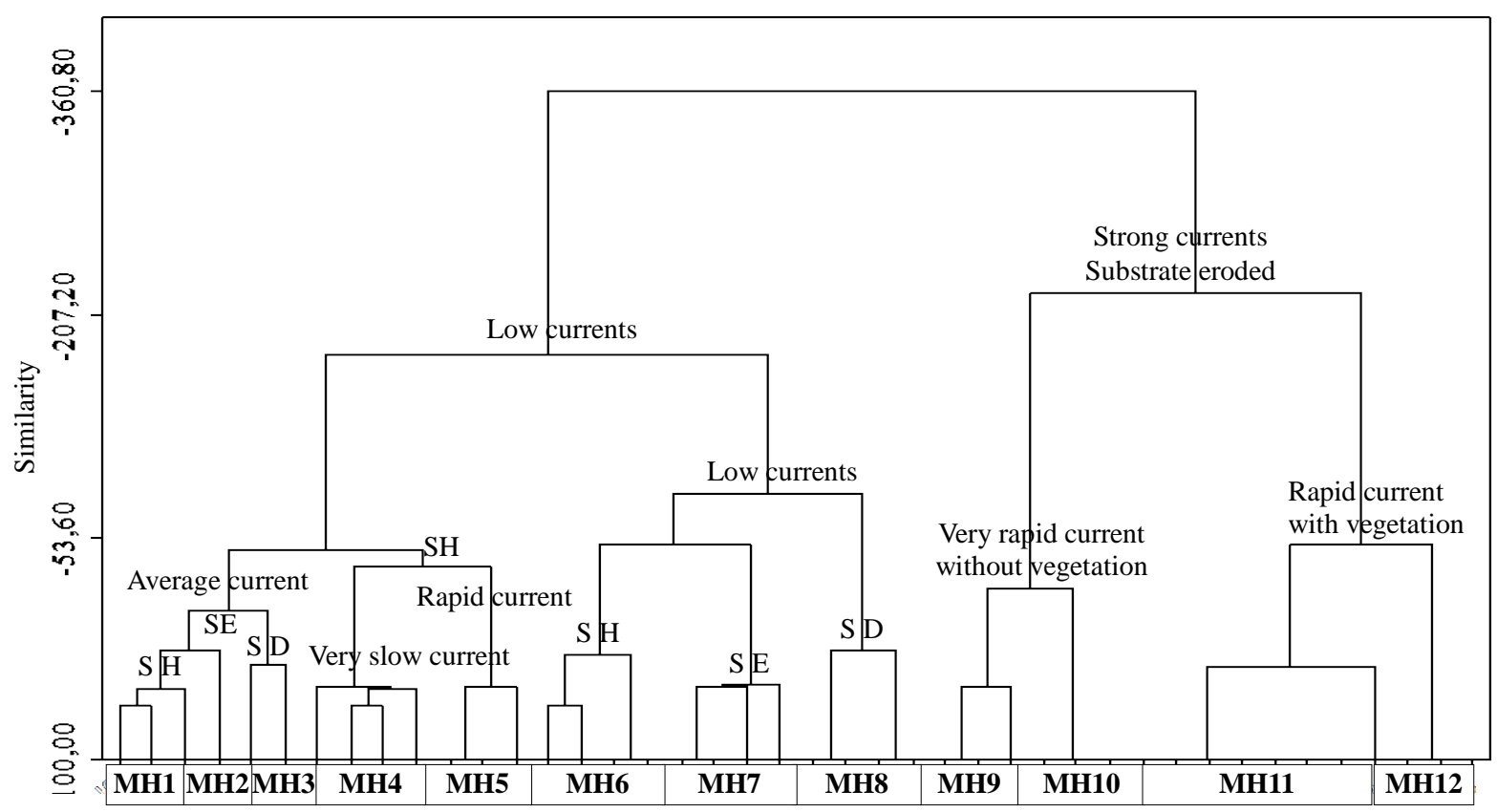

Figure 3. Dendrogram resulting from the physical characteristics of HCA microhabitats in the Tafna Basin of Algeria, defined by the current-substrate complex (SE = substrate eroded; $\mathrm{SH}=$ heterogeneous substrate; $\mathrm{SD}=$ substrate deposited).

microhabitat identified by the stream-substrate complex. The number of samples per microhabitat ranged from 1 to 7. Two large sets could be distinguished: (1) four microhabitats (MH 9-10-11-12) with strong currents on eroded substrate, including 17 samples (40.5\%), (2) eight microhabitats, including 22 samples (52.4\%) with low current and heterogeneous or deposited substrates, and three samples (7.1\%) with fast currents and heterogeneous substrates. Table 4 summarizes the characteristics of the 12 microhabitats, their occurrence (\%) and their location per station. The microhabitat MH11, with fast current and eroded substrate without vegetation, was distinguished by a higher importance (16.7\%). Microhabitats MH2 and MH3 were the least representative; they were characterized by an average current and eroded or deposited substrates. The nine remaining microhabitats had a similar number of samples ( 3 or 4). The distribution of these microhabitats per site (Table 4) indicated a clear between-station effect. Therefore, microhabitat MH11 was found at four sites, and remained fairly representative. The other microhabitats were found at 2 or 3 sites in upper (T.GB, T.AG, T.AZ) and middle (T.HB, T.RE, T.PC) Tafna and rarely in its tributaries (CH.Y, I.RE, I.OM). Microhabitat MH2, with an average current and eroded substrate, was represented by a single sample taken at station T.GB, downstream of the source of wadi Tafna.

\subsection{Microdistribution}

Analysis of simuliid distributions in the 12 defined microhabitats (Table 5) revealed that species richness, as well as abundance, varied from one microhabitat to another. On an eroded substrate and fast current (MH11), the maximum richness (eight species) was found, with high abundances, exceeding 1450 individuals for the $S$. ornatum (complex) and 900 individuals for $S$. trifasciatum. With the same specific richness, abundance was substantially lower for microhabitat MH6, which had heterogeneous substrate and slow current. However, the abundance decreased slightly (up to 78 individuals for S. pseudequinum) on eroded substrates covered with aquatic vegetation with a fast current (MH10). In contrast, microhabitats with deposited substrate had few individuals, especially microhabitat MH8 where the current was slow.

The most common species $S$. velutinum had less than 20 individuals. Intermediate values of species richness were observed in the other microhabitats, displaying abundances higher than 100 individuals for S. intermedium and S. trifasciatum in microhabitats MH4 and MH6 with heterogeneous substrates.

Species abundance differed according to the microhabitats (Table 5). Simulium velutinum was the most plastic and widespread, occuppying all types of microhabitats. It was followed by S. pseudequinum, S. trifasciatum 
Table 4. Characterization of microhabitats in the Tafna Basin of Algeria, determined by HCA according to the current-substrate couple and spatial distribution by microhabitat.

\begin{tabular}{|c|c|c|c|c|c|c|c|c|c|c|c|c|}
\hline \multirow[b]{2}{*}{ Microhabitat } & \multirow[b]{2}{*}{ Code } & \multicolumn{11}{|c|}{ Sampling sites } \\
\hline & & $\mathrm{p}$ & $F(\%)(p=42)$ & T.GB & T.AG & T.AZ & T.HB & T.PC & T.RE & I.OM & I.RE & CHY \\
\hline Mean current heterogeneous substrate & MH 1 & 3 & 7.14 & $\mathrm{X}$ & & & $\mathrm{X}$ & $\mathrm{X}$ & & & & \\
\hline Mean current substrate eroded & MH 2 & 1 & 2.38 & $\mathrm{X}$ & & & & & & & & \\
\hline Mean current substrate deposited & MH 3 & 2 & 4.76 & $\mathrm{X}$ & & $\mathrm{X}$ & & & & & & \\
\hline $\begin{array}{l}\text { Very slow current heterogeneous } \\
\text { substrate }\end{array}$ & MH 4 & 4 & 9.52 & & $\mathrm{X}$ & & & & & & & $\mathrm{X}$ \\
\hline Rapid current heterogeneous substrate & MH 5 & 3 & 7.14 & $\mathrm{X}$ & & & & $\mathrm{X}$ & & & & \\
\hline Slow current heterogeneous substrate & MH 6 & 4 & 9.52 & & $\mathrm{X}$ & & & & & & & $\mathrm{X}$ \\
\hline Slow current substrate eroded & MH 7 & 4 & 9.52 & & $\mathrm{X}$ & & & & $\mathrm{X}$ & & $\mathrm{X}$ & \\
\hline Slow current substrate deposited & MH 8 & 4 & 9.52 & & & $\mathrm{X}$ & $\mathrm{X}$ & & $\mathrm{X}$ & & & \\
\hline Very fast current substrate eroded & MH 9 & 3 & 7.14 & & & $\mathrm{X}$ & & & & & $\mathrm{X}$ & \\
\hline $\begin{array}{l}\text { Very fast current substrate eroded } \\
\text { with vegetation }\end{array}$ & MH 10 & 4 & 9.52 & & $\mathrm{X}$ & & & & & $\mathrm{X}$ & & \\
\hline Fast current substrate eroded & MH 11 & 7 & 16.66 & & $\mathrm{X}$ & $\mathrm{X}$ & & $\mathrm{X}$ & & & & $\mathrm{X}$ \\
\hline $\begin{array}{l}\text { Fast current substrate eroded with } \\
\text { vegetation }\end{array}$ & MH 12 & 3 & 7.14 & $\mathrm{X}$ & & & & $\mathrm{X}$ & $\mathrm{X}$ & & & \\
\hline
\end{tabular}

Table 5. Total number of specimens in 12 microhabitats of the Tafna Catchment, Algeria (March-November 2009).

\begin{tabular}{lcccccccccccc}
\hline Species & MH1 & MH2 & MH3 & MH4 & MH5 & MH6 & MH7 & MH8 & MH9 & MH10 & MH11 & MH12 \\
\hline S. quadrifila & 0 & 0 & 0 & 0 & 0 & 4 & 0 & 0 & 0 & 2 & 0 & 0 \\
S. galloprovinciale & 0 & 0 & 0 & 0 & 0 & 0 & 0 & 0 & 0 & 6 & 6 & 0 \\
S. sergenti & 0 & 0 & 1 & 0 & 0 & 4 & 0 & 0 & 0 & 0 & 13 & 0 \\
S. bezzii & 0 & 0 & 0 & 6 & 0 & 11 & 0 & 0 & 0 & 0 & 230 & 138 \\
S. pseudequinum & 3 & 0 & 1 & 1 & 25 & 23 & 1 & 0 & 364 & 92 & 304 & 84 \\
S. intermedium & 0 & 0 & 1 & 187 & 6 & 29 & 18 & 1 & 6 & 51 & 551 & 46 \\
S. velutinum & 51 & 4 & 62 & 61 & 49 & 11 & 161 & 17 & 269 & 42 & 434 & 193 \\
S. ornatum complex & 0 & 0 & 0 & 0 & 0 & 28 & 6 & 0 & 0 & 0 & 1455 & 0 \\
S. trifasciatum & 2 & 0 & 0 & 151 & 8 & 122 & 24 & 2 & 51 & 82 & 1657 & 50 \\
Species richness & $\mathbf{3}$ & $\mathbf{1}$ & $\mathbf{4}$ & $\mathbf{5}$ & $\mathbf{4}$ & $\mathbf{8}$ & $\mathbf{5}$ & $\mathbf{3}$ & $\mathbf{4}$ & $\mathbf{6}$ & $\mathbf{8}$ & $\mathbf{5}$ \\
Abundance & $\mathbf{5 6}$ & $\mathbf{4}$ & $\mathbf{6 5}$ & $\mathbf{4 0 6}$ & $\mathbf{8 8}$ & $\mathbf{2 3 2}$ & $\mathbf{2 1 0}$ & $\mathbf{2 0}$ & $\mathbf{6 9 0}$ & $\mathbf{2 7 5}$ & $\mathbf{4 6 5 0}$ & $\mathbf{5 1 1}$ \\
\hline
\end{tabular}

and $S$. intermedium, which were encountered in up to 10 microhabitats. These four species colonized habitats with fast and slow currents and different substrates.

Simulium bezzii was found in four microhabitats, with a significantly higher defined by the current-substrate complex. (SE = substrate eroded; $\mathrm{SH}=$ heterogeneous substrate; $\mathrm{SD}=$ substrate deposited) were characterized by fast current and eroded substrate, with or without vegetation.

The S. ornatum complex was found in three microhabitats; its presence in microhabitat MH11 was represented by more than 1450 individuals. Simulium sergenti accounted for only 18 individuals, of which 13 were in microhabitat MH11. A similar but smaller number of S. galloprovinciale was noted in microhabitats MH10 and MH11, each with a strong current and eroded substrate. The lowest abundance was found for $S$. qua- 
drifila with only eight individuals distributed among microhabitats MH6 and MH10.

\section{Discussion}

Of the 10 species in our samples, seven previously have been reported in Tafna catchment by Gagneur and Clergue-Gazeau [6]: S. velutinum, S. ruficorne, S. bezzii, S. intermedium, S. ornatum (complex), S. pseudequinum, and S. sergenti. They have also found in wadis of the Djurdjura Mountains in northern Algeria [8] and in the Seybouse River Basin in northeastern Algeria [10]. Simulium trifasciatum and S. quadrifila were reported recently in the checklist of Simuliidae of Algeria [9], and S. galloprovinciale was recorded for the first time in this work. Simulium quadrifila is a rare species, initially described as a subspecies of S. sergenti [19], then raised to species level by Crosskey [20]. This species has been reported in various localities in Spain [21] [22] and northern Morocco [23] [24].

The composition of the simuliid communities is similar between Tafna catchment and neighboring countries. With lower species richness (10 species), the recorded species in Tafna are among the 27 species known in Algeria [9], the 42 species in Morocco [25], and the 50 species in Spain [26]. In the eastern Mediterranean, 12 species were reported in Lebanon [27], with three species in common with ours, namely S. bezzii, S. ornatum complex, and S. peudequinum, and 63 species are known in Turkey [28] with six species in common with ours. Five species are also in common with the Tunisian fauna, which includes 18 species [29]. The number of simuliid species collected is relatively low compared to other catchment in Maghreb. Lounaci [8] identified 19 species in Sebaou Basin, Belqat [30] reported 14 species in Laou Basin, and Guidicelli [31] found 24 species in the High Atlas. Eight nominal species and species complexes in three genera were identified in the Seybouse River Basin in northeastern Algeria [10]. Simulium bezzi and S. (S.) ornatum were also found in Pyrenean rivers [32]-[35]. The low diversity of black flies in two catchments in southern Spain was noted by Gallardo-Mayenco and Toja [36] who reported values of $H^{\prime}$ less than 1.

The presence of larvae and pupae of black flies in Tafna catchment is linked to the availability of favorable habitats, especially with high current and eroded substrate. These restricted habitats (30\%) limit the simuliids, which are known for their rheophily and preference for hard, coarse substrates (rocks, stones, pebbles) [7] [31]. This probably explains their absence in $70 \%$ of samples characterized by deposited substrates (fine elements) and bottoms colonized by aquatic vegetation.

Simuliid distributions in the Tafna catchment were determined, in part, by the station effect. This spatial variability has been demonstrated in several studies in which altitude played an important role [37]-[40]. Studies [31] [41] revealed that simuliid distributions depend on two main physical factors: water temperature and altitude. However, in our study, the effect of distance from the source, which is related to altitude, is not significant. Current and substrate are key parameters determining microhabitats in sites of the Tafna catchment. The four most abundant species in Tafna basin are S. velutinum, S. trifasciatum, S. intermedium and S. pseudequinum, compared with three (S. velutinum, S. intermedium and S. pseudequinum) in Sebaou basin where S. trifasciatum is absent. Larvae and pupae of these species are abundant in shallow waters, rich in organic material and filamentous algae [8]. The ability of these species to inhabit a large range of ecological factors was reported by several authors [6] [7] [21] [31] [36]. Larvae of S. velutinum are found at moderate velocities, but also can be found in slow currents [24]. Simulium intermedium colonizes temporary, semi-permanent and permanent habitats with variable substrates and low to average velocities [24]. It can develop in waters heavily loaded with organic material [24] [42]. In Europe, S. trifasciatum is confined to small streams with stony substrates and slow current and abundant vegetation [21], and in highly oxygenated waters [22]. In Morocco, this species appears to be a strictly montane form that colonizes substrates in moderate to fast currents [30] [41] [43]. In Turkey, it is associated with calcareous waters of the sources [44]. Simulium pseudequinum is collected in large numbers in microhabitats with eroded substrate and fast currents, with or without vegetation, but rarely in slow currents. This Palaearctic species, widely represented in England [45], is common in Morocco [30] and Tunisia [46] in all habitats, especially those with rocky substrates. Simulium bezzii is limited to three sites in the upper Tafna basin and colonizes microhabitats with eroded bottoms swept by fast current. In the northern Mediterranean, it is associated with mountain and piedmont streams with fast flow and rocky bottoms [32]-[34] [38]. In Morocco, $S$. bezzii is found on muddy bottoms with stones and slow to fast currents [24].

Belqat [24] considered sympatry of $S$. intermedium and S. ornatum (complex) to be typical in Morocco. However, this sympatry is rather rare in Portugal and Spain [47] [48]. These observations are comparable with 
ours; the two species coexist only in three microhabitats out of 12 . The $S$. ornatum (complex) is abundant in fast currents with eroded bottoms near the source of wadi Chouly (tributary of wadi Tafna), whereas it is scarce in slow currents with heterogeneous or eroded substrate. Gagneur [8] reported this species in the crenal of Tafna catchment, and Guidicelli [31] considered it more rithrophilic in the High Atlas. In the extreme north of Tunisia, larvae and pupae of the $S$. ornatum complex were found in low abundance in rapid and highly oxygenated streams with abundant vegetation [46]. This species complex usually inhabits Pyrenean streams with slow current and aquatic vegetation rich in macrophytes [33] [34].

The less abundant species (S. quadrifila and S. sergenti) in our samples have been found in slow and fast currents with heterogeneous substrate. Their habitats in Europe and Morocco are similar [19] [21] [23] [24].

Equally rare in our samples, S. galloprovinciale is restricted to microhabitats with rocky substrates eroded by strong currents. This species, known in southwestern Europe, has been described as rheophilic [49]. It was collected in streams of the Rif Mountains in Morocco, but always confined to fast currents. Pupal cocoons from wadi Chouly in upper Tafna, were covered with calcareous concretions [24].

The ecological features associated with the wadis of the Tafna catchment demonstrated the diversity of habitats available to black flies. The low altitudinal variation $(<1090 \mathrm{~m})$ partly explains the degree of absence of simuliids in the Tafna catchment. Future studies of other environments (e.g., springs and coastal wadis), with analysis of their distributions according to environmental factors, such as temperature, altitude, and chemical analyses of waters (e.g., dissolved oxygen, orthophosphates, nitrites and nitrates) would improve the understanding of the ecological requirements of the black flies in Algeria.

\section{References}

[1] Grenier, P. (1953) Simuliidae de France et d’Afrique du Nord. Encyclopédie Entomologie Lechevalier P., Paris, 170p.

[2] Roubaud, M.E. (1906) Aperçus nouveaux morphologiques et biologiques sur les Diptères piqueurs du groupe Simulies. Compte Rendu de l'Académie des Sciences Paris, 143, 519-521.

[3] Edward, F.W. (1923) On Some Algerian Species of Simulium. Archive Institut Pasteur d'Algérie, 1, 647-653.

[4] Parrot, L. (1949) Quelques notes sur les Simulies d’Algérie. Archive Institut Pasteur, Algérie, 27, $273-275$.

[5] Vaillant, F. (1955) Recherches sur la faune de France, de Corse et d'Afrique du Nord. Mémoire du Museum Histoire Naturelle Paris (Zoologie), 11, 1-258 + VI pl.

[6] Gagneur, J. and Clergue-Gazeau, M. (1988) Les Simulies d’Algérie (Diptera: Simuliidae). I. Premières données biogéographiques et écologiques sur les espèces de l’Ouest algérien. Annales de Limnologie, 24, 275-284. http://dx.doi.org/10.1051/limn/1988024

[7] Clergue-Gazeau, M., Lek, S. and Lek, S. (1991) Les Simulies d’Afrique du Nord. Nouvelles données sur la répartition de la faune du Maroc et biogéographie des espèces maghrébines (Diptera, Simuliidae). Revue d'hydrobiologie tropicale, 24, 47-59.

[8] Lounaci, A., Brosse, S., Thomas, A. and Lek, S. (2000) Abundance, Diversity and Community Structure of MacroInvertebrates in an Algerian Stream: the Sébaou wadi. Annales de Limnologie, 36, 123-133. http://dx.doi.org/10.1051/limn/2000008

[9] Chaoui Boudghane-Bendiouis, C., Belqat, B., Hassaine-Abdellaoui, K. and Yadi, B. (2012) Check-list des simulies (Diptera: Simuliidae) d'Algérie. Boletin de la Sociedad Entomológica Aragonesa (S.E.A.), 50, 305-308.

[10] Cherairia, M., Adler, P.H. and Samraoui, B. (2014) Biodiversity and Bionomics of the Black Flies (Diptera: Simuliidae) of Northeastern Algeria. Zootaxa, 3796, 166-174. http://dx.doi.org/10.11646/zootaxa.3796.1.8

[11] Cummins, K.W. and Lauff, G.H. (1969) The Influence of Substrate Particle Size on the Microdistribution of Stream Macrobenthos. Hydrobiologia, 34, 145-181. http://dx.doi.org/10.1007/BF00141925

[12] Bournaud, M. and Cogerino, L. (1986) Les microhabitats aquatiques des rives d'un grand cours d'eau: Approche faunistique. Annales de Limnologie, 22, 285-294. http://dx.doi.org/10.1051/limn/1986026

[13] Bournaud, M., Tachet, H., Berly, A. and Cellot, B. (1998) Importance of Microhabitat Characteristics in the Macrobenthos Microdistribution of a Large River Reach. Annales de Limnologie, 34, 83-98. http://dx.doi.org/10.1051/limn/1998009

[14] Franquet, E. (1999) Chironomid Assemblage of a Lower-Rhône Dike Field: Relationships between Substratum and Biodiversity. Hydrobiologia, 397, 121-131. http://dx.doi.org/10.1023/A:1003681817806

[15] Benest, M. (1985) Evolution de la plate-forme de l’Ouest Algérien et du Nord-Est Marocain au cours du Jurassique supérieur et au début du Crétacé: Stratigraphie, milieux de dépôts et dynamique sédimentaire. Thèse de doctorat, Documents Laboratoire Géologique Lyon, 381 p. 
[16] Bensaoula, F. (2007) Etude de la karstification à partir des données de forages: Le cas des Monts de Tlemcen (Algérie). Karstologia, 49, 15-24.

[17] Bouanani, A. (2004) Hydrologie, transport solide et modélisation: Etude de quelques sous bassins de la Tafna (NWAlgérie). Thèse, Université d’Oran, 245 p.

[18] Belqat, B. and Dakki, M. (2004) Clés analytiques des Simulies (Diptera) du Maroc. Zoologica Baetica, 15, 77-137.

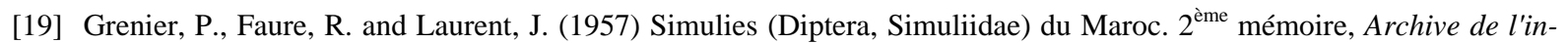
stitut Pasteur, 5, 218-242.

[20] Crosskey, R.W. (1969) The Re-Classification of Simuliidae of Africa and Its Islands. Bulletin of the British Museum (Natural History-Entomology), 14, 1-195.

[21] Beaucournu-Saguez, F. (1975) Récoltes de Simulies (Diptera: Simuliidae) dans le Sud-Est de l’Espagne. Annales de la Société Entomologique de France, 11, 73-89.

[22] Gonzàlez-Peña, G. (1990) Sistema y ecología de los Simuliidae (Diptera) de los ríos de Catalunya y de otras cuencas hidrográficas Españolas. Tesis Doctoral, Facultad de Biología Murcia, 451 p.

[23] Choumara, H. and Beaucournu-Saguez, F. (1978) Contribution à l'étude des Simulies du Maroc. I. Le rif. Bulletin Institut Scientifique de Rabat, 3, 121-144.

[24] Belqat, B. (2002) Etude systématique, écologique et caryologique des Simulies (Diptera: Simuliidae) du Maroc: Cas particulier du Rif. Thèse d'Etat es Sciences, université Abdelmalek Essaâdi, faculté des sciences, Tétouan.

[25] Belqat, B., Adler, P.H. and Crosskey, R.W. (2011) Faunistic and Bibliographical Inventory of the Blackflies (Diptera: Simuliidae) of Morocco. Zootaxa, 2829, 46-58.

[26] Belqat, B. and Garrido, J. (2008) Inventaire faunistique et bibliographique des Simulies d'Espagne (Diptera, Simuliidae). Nouvelle Revue d'Entomologie (N.S.), 24, 201-219.

[27] Moubayed, Z. and Clergue-Gazeau, M. (1985) Les Simuliidae (Diptera) de trois rivières Oronte, Litani et Beyrouth du Liban. Annales de Limnologie, 21, 83-88. http://dx.doi.org/10.1051/limn/1985008

[28] Kazanci, N. and Ertunç, Ö. (2008) Checklist of the Simuliidae (Insecta, Diptera) of Turkey. Review of Hydrobiology, 2, 129-144.

[29] Kazanci, N. and Ertunç, Ö. (2008) On the Simuliidae (Insecta, Diptera) Fauna of Turkey. Review of Hydrobiology, 1, 27-36.

[30] Belqat, B., Bennas, N., El Alami, M., Kettani, K. and Aoulad Ali, S. (2008) Faune simulidienne du bassin versant Laou. Travaux de l'Institut Scientifique Rabat, 5, 61-66.

[31] Giudicelli, J., Bouzidi, A. and Ait Abdelaali, N. (2000) Contribution à l'étude faunistique et écologique des simulies (Diptera: Simuliidae) du Maroc. IV. Les simulies du Haut Atlas. Description d'une nouvelle espèce. Annales de Limnologie, 36, 57-80. http://dx.doi.org/10.1051/limn/2000005

[32] Clergue-Gazeau, M. and Cazagnes, G. (1986) Les Simuliidae (Diptera: Nematocera) de la Neste d’Aure (Pyrénées Centrales). I. Impact des aménagements hydroélectriques dans la haute vallée. Annales de Limnologie, 22, 195-203. http://dx.doi.org/10.1051/limn/1986017

[33] Clergue-Gazeau, M., Holmière, D., Meurgues, S. and Angelier, E. (1987) Les Simuliidae (Diptera, Nematocera) de la Neste d’Aure (Hautes-Pyrénées). II. Ecologie et impact des aménagements dans la moyenne et la basse vallée. Annales de Limnologie, 23, 197-207. http://dx.doi.org/10.1051/limn/1987018

[34] Vinçon, G. and Clergue-Gazeau, M. (1988) Etude hydrobiologique de la vallée d’Ossau (Pyrénées Atlantiques, France). III. Simuliidae (Diptera, Nematocera): Leur originalité biogéographique et écologique. Annales Limnologie, 24, 67-81. http://dx.doi.org/10.1051/limn/1988007

[35] Céréghino, R. and Lavandier, P. (1997) Influence des éclusées hydroélectriques sur la distribution et le développement larvaire des Diptères Simuliidae d'une rivière de moyenne montagne. Life Sciences, 320, 329-338.

[36] Gallardo-Mayenco, A. and Toja, J. (2002) Spatio-Temporal Distribution of Simuliids (Diptera) and Associated Environmental Factors in Two Mediterranean Basins of Southern Spain. Limnetica, 21, 47-57.

[37] Gonzàlez, G. (1980) Primeres dades sobre la distribució dels Simuliidae (Diptera, Nematocera) d’Andorra. Bulletin Institut Catalan Histoire Naturelle, 45, 97-106.

[38] Vinçon, G. and Clergue-Gazeau, M. (1993) Les Simulies (Diptera Simuliidae) du Sud-Ouest de l’Europe: Le crénal et l’épirhithral. Annales Limnologie, 29, 157-169. http://dx.doi.org/10.1051/limn/1993014

[39] Ofenböck, T., Moog, O. and Car, M. (2002) Do Austrian Blackfly Fauna (Diptera: Simuliidae) Support the Typological Approach of the EU Water Framework. Limnologica, 32, 255-272. http://dx.doi.org/10.1016/S0075-9511(02)80032-9

[40] Kazanci, N. (2006) Ordination of Simuliidae and Climate Change Impact. Acta Entomologica Serbica, 11, 69-76. 
[41] Belqat, B., Dakki, M. and El Alami, M. (2005) Estructura Biotipológica de las principales redes hidricas Rifeñas a través de los Simúlidos (Diptera: Simuliidae). Ecosistemas, 14, 50-56.

[42] Rivosecchi, L. (1978) Simuliidae: Diptera, Nematocera. Fauna d’Italia, 13. Calderini, Bologna.

[43] Belqat, B., Dakki, M. and Errami, M. (2001) Deux nouvelles Simulies pour le Nord de l'Afrique: Simulium (Nevermannia) angustitarse et Simulium (Simulium) trifasciatum. British Simuliid Group Bulletin, 17, 7-10.

[44] Crosskey, R.W. (1987) An Annotated Checklist of the World Blackflies (Diptera, Simuliidae). In: Kim, K.C. and Merritt, R.W., Eds., Black Flies: Ecology, Population Management, and Annotated World List. Pennsylvania State University Press, University Park and London, 425-520.

[45] Crosskey, R.W. (1981) The Identity and Synonymy of S. (W.) Pseudequinum Séguy and Occurrence of This Species in England (Diptera: Simuliidae). Entomologist's Gaz, 32, 137-148.

[46] Boumaiza, M. and Clergue-Gazeau, M. (1986) Le peuplement simulidien de la Tunisie. I. Inventaire, faunistique et biogéographie (Diptera-Nematocera). Annales de Limnologie, 22, 31-39. http://dx.doi.org/10.1051/limn/1986003

[47] Santos Gracio, A. (1985) Estudo Sistematico e bioecológico dos Simulideos de Portugal (Diptera: Simuliidae). Doctoral dissertation, New University of Lisbon, Lisbon. (In Portuguese)

[48] Crosskey, R.W. and Crosskey, M. (2000) An Investigation of the Blackfly Fauna of Andalousia, Southern Spain (Diptera: Simuliidae). Journal of Natural History, 34, 895-951. http://dx.doi.org/10.1080/002229300299309

[49] Giudicelli, J. (1962) Simulium galloprovinciale n. sp. (Diptera: Simuliidae), une simulie nouvelle du groupe auricoma. Comparaisons avec les espèces du genre Obuchovia Rubzov 1951. Bulletin Société Pathologie Exotique, 55, 882-892. 
Scientific Research Publishing (SCIRP) is one of the largest Open Access journal publishers. It is currently publishing more than 200 open access, online, peer-reviewed journals covering a wide range of academic disciplines. SCIRP serves the worldwide academic communities and contributes to the progress and application of science with its publication.

Other selected journals from SCIRP are listed as below. Submit your manuscript to us via either submit@scirp.org or Online Submission Portal.
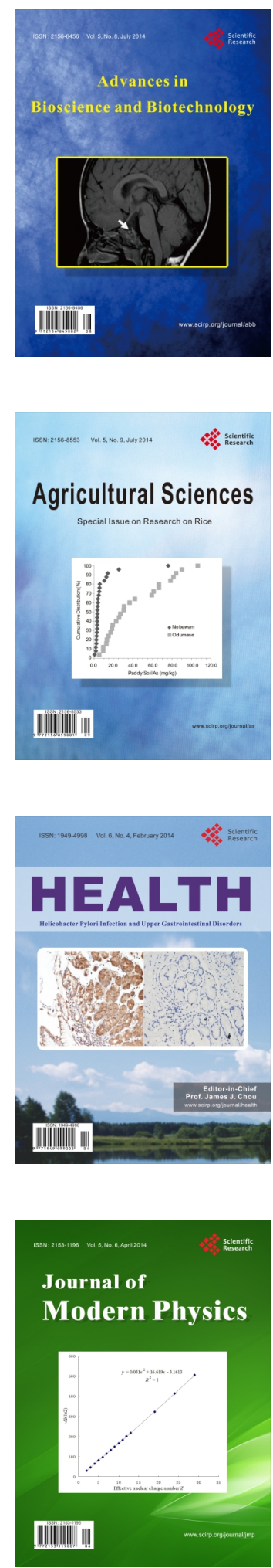
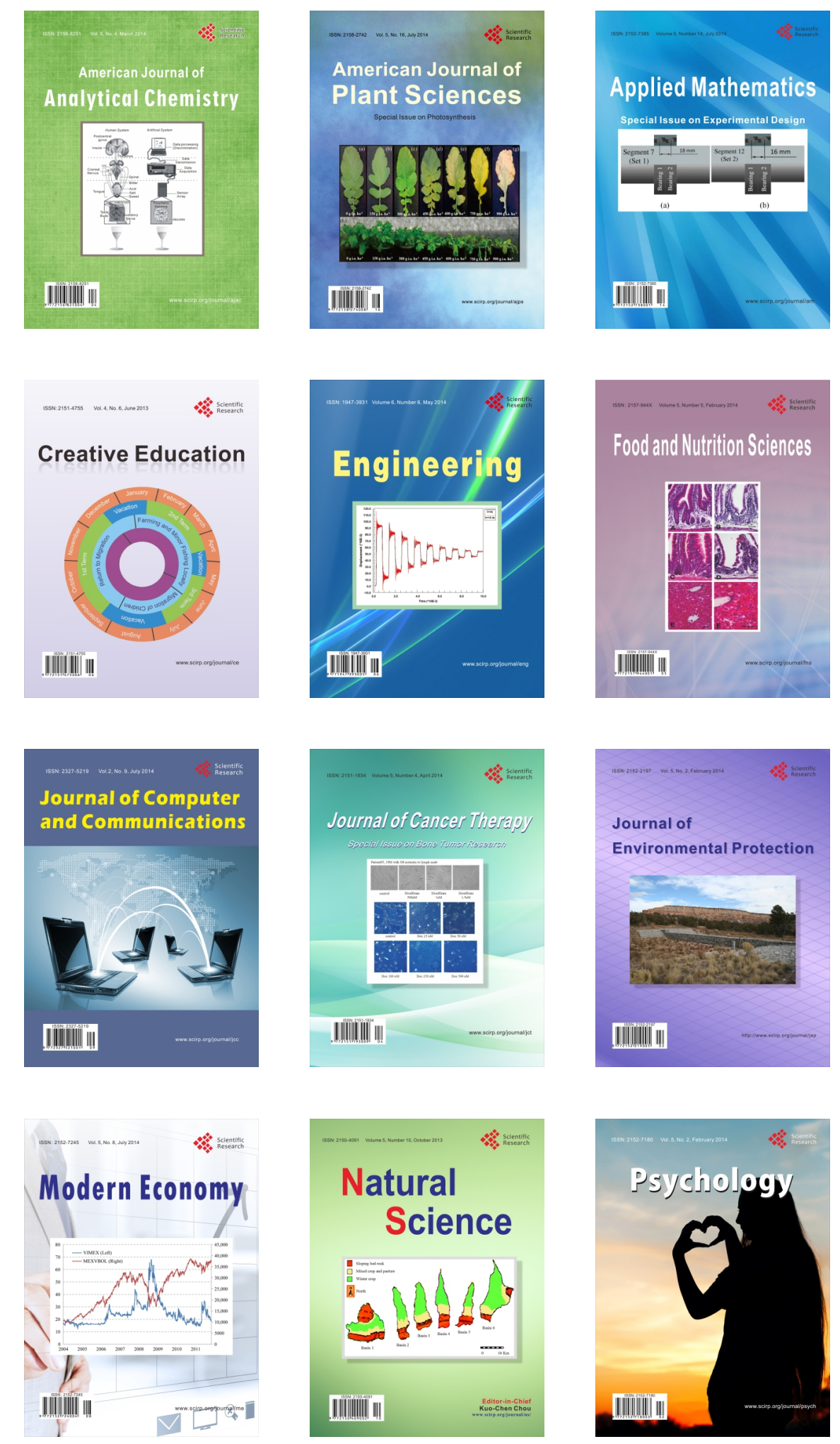